\title{
Erratum to: Population-Based Prevention of Child Maltreatment: The U.S. Triple P System Population Trial
}

\author{
Ronald J. Prinz • Matthew R. Sanders • \\ Cheri J. Shapiro • Daniel J. Whitaker • John R. Lutzker
}

Published online: 9 December 2014

(C) Society for Prevention Research 2014

\section{Erratum to: Prev Sci (2009) 10:1-12 \\ DOI 10.1007/s11121-009-0123-3}

The Journal regrets that although provided by the authors prior to publication, the original version of this article inadvertently did not include the following disclosure of Conflict of Interest:

\section{Conflict of Interest}

The Triple P-Positive Parenting Program is owned by The University of Queensland. The University, through its technology transfer company Uniquest Pty Ltd., has licensed Triple P International Pty Ltd. to disseminate the program worldwide. Royalties stemming from this dissemination work are paid to UniQuest, which distributes payments to the
University of Queensland Faculty of Health and Behavioural Sciences. School of Psychology, Parenting and Family Support Centre, and contributory authors in accordance with the University's intellectual property policy. No author has any share or ownership in Triple P International. Matthew Sanders is the founder and lead author of the Triple P-Positive Parenting Program, and is a consultant to Triple P International. Ronald Prinz previously held the sublicense for dissemination of Triple $P$ in the U.S., which is now retained exclusively by Triple P International and the University of Queensland. Cheri Shapiro is a consultant to Triple P America. Daniel Whitaker and John Lutzker have no competing interests. The University of South Carolina's Office of Research Compliance in conjunction with the $\mathrm{CDC}$ assisted the investigators with protection of the integrity of the research on which this article was based.

The online version of the original article can be found at http://dx.doi.org/ 10.1007/s11121-009-0123-3.

R. J. Prinz $(\bowtie) \cdot$ C. J. Shapiro

Psychology Department, University of South Carolina,

Columbia, SC 29208, USA

e-mail: prinz@sc.edu

\section{R. Sanders}

University of Queensland,

Brisbane, Australia

D. J. Whitaker · J. R. Lutzker

Georgia State University,

Atlanta, GA, USA 